\title{
Arginine-Rich Regions Mediate the RNA Binding and Regulatory Activities of the Protein Encoded by the Drosophila melanogaster suppressor of sable Gene
}

\author{
MICHAEL A. TURNAGE, $\uparrow$ PAUL BREWER-JENSEN, WEN-LI BAI, AND LILLIE L. SEARLES* \\ Department of Biology and Curriculum in Genetics and Molecular Biology, University of North Carolina \\ at Chapel Hill, Chapel Hill, North Carolina 27599-3280
}

Received 30 May 2000/Returned for modification 11 July 2000/Accepted 1 August 2000

\begin{abstract}
The Drosophila melanogaster suppressor of sable gene, su(s), encodes a novel, 150-kDa nuclear RNA binding protein, $\mathrm{SU}(\mathrm{S})$, that negatively regulates RNA accumulation from mutant alleles of other genes that have transposon insertions in the $5^{\prime}$ transcribed region. In this study, we delineated the RNA binding domain of $\mathrm{SU}(\mathrm{S})$ and evaluated its relevance to $\mathrm{SU}(\mathrm{S})$ function in vivo. As a result, we have defined two arginine-rich motifs (ARM1 and ARM2) that mediate the RNA binding activity of SU(S). ARM1 is required for in vitro high-affinity binding of SU(S) to small RNAs that were previously isolated by SELEX (binding site selection assay) and that contain a common consensus sequence. ARM1 is also required for the association of SU(S) with larval polytene chromosomes in vivo. ARM2 promotes binding of SU(S) to SELEX RNAs that lack the consensus sequence and apparently is neither necessary nor sufficient for the stable polytene chromosome association of $\mathrm{SU}(\mathrm{S})$. Use of the GAL4/UAS system to drive ectopic expression of $s u(s)$ cDNA transgenes revealed two previously unknown properties of $\mathrm{SU}(\mathrm{S})$. First, overexpression of $\mathrm{SU}(\mathrm{S})$ is lethal. Second, SU(S) negatively regulates expression of $s u(s)$ intronless cDNA transgenes, and the ARMs are required for this effect. Considering these and previous results, we propose that $S U(S)$ binds to the $5^{\prime}$ region of nascent transcripts and inhibits RNA production in a manner that can be overcome by splicing complex assembly.
\end{abstract}

Eukaryotic protein-coding RNAs are typically transcribed as larger pre-mRNAs that are processed to a mature form. PremRNA processing is coupled to transcription $(7,8,27,42)$ and involves a complex set of events including the addition of a 7-methylguanosine cap to the $5^{\prime}$ end, splicing to remove internal introns, and cleavage/polyadenylation of the $3^{\prime}$ end. Interactions between the cellular transcription and RNA processing apparatuses and between RNA processing components that assemble at various sites on the pre-mRNA are thought to facilitate the efficient production of mRNAs that are suitable substrates for translation. Incorrectly processed transcripts can be recognized as such and degraded $(16,24,26,40)$.

The Drosophila melanogaster suppressor of sable gene, su(s), encodes a protein involved in nuclear pre-mRNA metabolism. Loss-of-function $s u(s)$ mutations either suppress or enhance specific mutant alleles of a variety of unlinked genes (49). Some $s u(s)$ mutants also exhibit defects in viability and male fertility (52). Although both the $s u(s)$ gene and mutant alleles affected by $s u(s)$ have been cloned and characterized, the function of the $s u(s)$ gene product, $\mathrm{SU}(\mathrm{S})$, has been somewhat elusive. The enhanced alleles are associated with large, complex genes that cannot easily be analyzed in detail at a molecular level. More is known about the suppressed alleles, through molecular studies of vermilion $(v)$, yellow $(y)$, and purple $(\mathrm{pr})$ $(20-22,29)$. The $s u(s)$-suppressible mutations have transposon insertions near the $5^{\prime}$ end of the transcribed region that interrupt either the first exon or the first intron. These mutant genes produce a reduced level of RNA in $s u(s)^{+}$flies, and RNA levels are elevated in $s u(s)$ mutants. The RNAs generated

\footnotetext{
* Corresponding author. Mailing address: Department of Biology, CB\# 3280, UNC at Chapel Hill, Chapel Hill, NC 27599-3280. Phone: (919) 966-4989. Fax: (919) 962-1625. E-mail: lsearles@email.unc.edu. $\dagger$ Present address: Department of Botany, North Carolina State University, Raleigh, NC 27695.
}

initiate at the normal transcription start site of the genes. Antisense transposon sequences are incorporated into the premRNA and can be removed during splicing. In the case of $v$ and $y$, transposon sequences are removed inefficiently by splicing at cryptic splice sites near the ends of the inserted sequences $(20,22)$. Previous work from this lab demonstrated that the improvement of a cryptic 5' splice site near the beginning of a mutant $v$ transgene to a consensus site increased RNA production from a mutant $v$ transgene, without improving the splicing efficiency. This change also eliminated the inhibition of RNA production by SU(S) (21). While these and other studies have established a connection between $\mathrm{SU}(\mathrm{S})$ mediated regulation of RNA levels and the efficiency of splicing complex assembly in the $5^{\prime}$ region of the pre-mRNA (21, $29)$, the mechanism by which $\mathrm{SU}(\mathrm{S})$ regulates accumulation of these RNAs has not been established. Thus, it is unclear whether SU(S) directly regulates transcription, splicing complex assembly, or pre-mRNA stability.

$\mathrm{SU}(\mathrm{S})$ is a novel, $150-\mathrm{kDa}$ nuclear protein. The initial sequence analysis (51) defined two regions of SU(S) with similarity to structural motifs found in RNA processing proteins, a highly charged region in the N-terminal portion of $\mathrm{SU}(\mathrm{S})$ and an RNA recognition motif-like motif in the C-terminal region. The importance of these regions to $\mathrm{SU}(\mathrm{S})$ function has not been determined. Subsequently, two tandem copies of a $\mathrm{CCCH}$ zinc binding domain (57) of unknown function were identified within SU(S) (43). This motif is also found in several other eukaryotic proteins, including the Caenorhabditis elegans transcriptional repressor PIE-1 $(6,43)$, the mRNA destabilization protein TTP/Nup475/TIS11 (12, 32), the 35-kDa subunit of the splicing factor U2AF $(43,48)$, and the $30-\mathrm{kDa}$ subunit of the polyadenylation factor CPSF (3-5).

Recombinant $\mathrm{SU}(\mathrm{S})$, expressed in baculovirus, binds to RNA in vitro; using a PCR-based binding site selection assay (SELEX), we isolated high-affinity RNA substrates (45). In 
this paper, we have delineated the RNA binding domain of $\mathrm{SU}(\mathrm{S})$ and examined its role in SU(S) function in vivo. Based on the results presented here and previous studies, we propose that $\mathrm{SU}(\mathrm{S})$ binds to the $5^{\prime}$ region of the nascent transcripts via arginine-rich RNA binding motifs (ARMs) and inhibits RNA production in a way that can be overcome by splicing complex assembly in the $5^{\prime}$ region.

\section{MATERIALS AND METHODS}

Generation and analysis of MBP-SU(S) fusion derivatives. In mapping the RNA binding regions, a 1,084-bp ClaI-ScaI su(s) cDNA fragment that encodes the first 360 amino acids of SU(S) was used to generate smaller fragments by digestion with either appropriate restriction enzymes or exonuclease III. Subsequently, these fragments were cloned into the maltose binding protein (MBP) expression vector pPR997 (New England Biolabs). Deletions of sequences encoding the two ARMs of SU(S) were introduced using overlapping PCR mutagenesis (25). Unique $X b a \mathrm{I}$ and HindIII restriction sites were introduced at the site of the ARM1 and ARM2 deletions, respectively, to facilitate identification of clones containing the desired changes. Convenient restriction sites were used to introduce fragments containing either one or both deletions into pMALSU(S) ${ }_{1-434}$, an MBP-SU(S) fusion encoding amino acids 1 to 434. In addition, small PCR-generated fragments containing the coding region for ARM1 and ARM2 alone were cloned into pPR997. Prior to affinity purification of the fusion proteins as described previously (45), clones were sequenced to ensure that undesirable alterations were not introduced during the PCRs. RNA binding activity of the MBP-SU(S) fusions was measured by nitrocellulose filter binding and Northwestern blot assays as described previously (45). $K_{d} \mathrm{~s}$ were determined using SigmaPlot (Jandel Scientific). Under the conditions of these experiments, the $K_{d}$ is equal to the protein concentration that results in $50 \%$ of the maximal RNA binding.

Construction of clones for germ line transformations. An approximately 4-kb XhoI-SpeI cDNA fragment containing the $s u(s)$ coding region from either the wild type or $\triangle \mathrm{ARM}$ derivatives was cloned into XhoI-XbaI-digested plasmid pUAST (9). These clones were injected into $y w$ embryos, and germ line transformants were isolated essentially as described by Karess (28). Standard balancer chromosomes were used to establish homozygous stocks of $w^{+}$transformant lines and to cross the transgenes into the background of $s u(s)$ mutants.

Viability studies. GAL4-expressing stocks were obtained from the Bloomington Stock Center and crossed to stocks of transformants carrying $U A S$-su(s) transgenes. The expression patterns of the GAL4 drivers are described in Flybase (http://flybase.bio.indiana.edu). To examine the viability of flies ectopically expressing SU(S) under control of different GAL4 drivers, crosses were set up with a single vial for each transformant. The flies were reared at $18^{\circ} \mathrm{C}$. All except one of the crosses involved balanced GAL4 driver stocks, and viability was assessed by determining the proportion of progeny that lacked the balancer chromosome. One stock, 1799, was homozygous for the heat-shock inducible GAL4 driver (hs-GAL4). Thus, all of the progeny would be expected to express the $U A S$-su(s) transgene. Vials yielding normal numbers of progeny were scored as $100 \%$ viable; therefore, this value in this particular cross is only an approximation.

The crosses between transformants carrying either a wild-type $s u(s)[s u(s) w t]$ or $s u(s) \triangle A R M$ transgene and GAL4 stock 2023 were performed in the following way. Three vials, each containing five pairs of virgin females and males, were set up for each transformant line tested. Crosses were performed at 25 and at $18^{\circ} \mathrm{C}$; progeny were collected and scored for 10 and 20 days, respectively.

RNA analysis. Total RNA was isolated essentially as described previously (15), and polyadenylated RNA was purified from the total RNA preparations by using a Poly ATtract mRNA isolation kit (Promega). Northern analysis was performed as described previously (21). The probe used for Northern analysis was a $\mathrm{Cla} \mathrm{I} /$ $\mathrm{DraI} s u(s)$ cDNA fragment from plasmid p15-1, labeled by random priming (2). RNase protection experiments were performed as described in Current Protocols in Molecular Biology (2). Each reaction contained $20 \mu \mathrm{g}$ of total RNA. The probes used were radioactively labeled, antisense RNAs of an XmaI/BamHI $s u(s)$ cDNA fragment containing portions of exons 3 and 4, and $r p 49$ (21) was used as the internal control. The probes were labeled by in vitro transcription as described previously (21)

Protein analysis. Whole cell extracts were prepared by grinding 25 to $30 \mathrm{mg}$ of frozen adult flies in $100 \mu \mathrm{l}$ of $1.5 \times$ sodium dodecyl sulfate (SDS) sample buffer (6× SDS sample buffer is $0.35 \mathrm{M}$ Tris- $\mathrm{Cl}$ [pH 6.8], $10 \%$ SDS, $93 \mathrm{mg}$ dithiothreitol per $\mathrm{ml}$, and $30 \%$ glycerol) on ice. Samples were boiled for $10 \mathrm{~min}$ prior to a 10 -min centrifugation at $13,000 \times g$. The supernatant was assayed for protein content by the Bradford method using the Bio-Rad protocol. Proteins were resolved by SDS-polyacrylamide gel electrophoresis, and Western blots were probed with a 1:1,000 dilution of an affinity-purified polyclonal antibody directed against SU(S) amino acids 42 to 146 . Horseradish peroxidase-conjugated goat anti-rabbit antibody (Promega) was used as the secondary antibody, and bands were visualized by enhanced chemiluminescence detection (Amersham) as recommended by the manufacturer.

Immunocytochemistry. Polytene chromosome squashes of third-instar larval salivary glands were prepared and immunostained as described by Ashburner
A

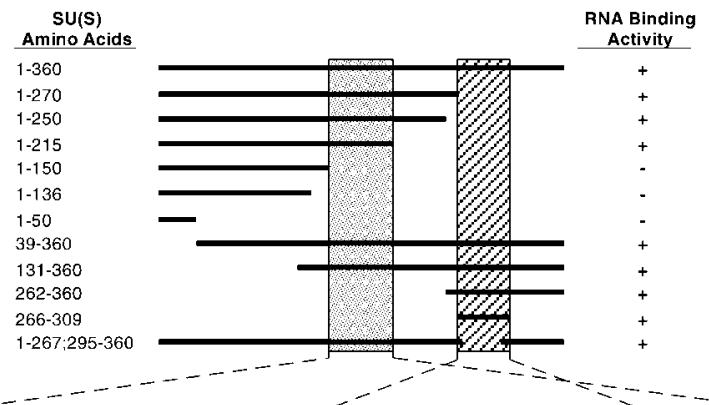

RRRKRKKEREREQKKDKEQQNRSRRDENDVSVVPGGVEDMDEYEMMNVRGGSPPPPGGAAPPLS MNORRRTRRDNEKEHQRGVNNRKRRDRDRLEGGLAGSGSKRNRRD

B

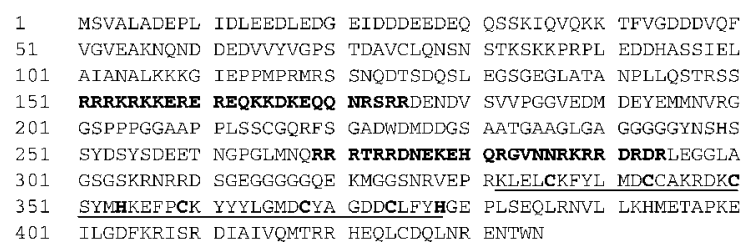

FIG. 1. (A) Delineation of the SU(S) RNA binding domain. MBP-SU(S) fusion proteins containing different portions of the first 360 amino acids of SU(S) were evaluated for binding to radioactively labeled $\mathrm{ftz}$ pre-mRNA by nitrocellulose filter binding or blot overlay assays. Plus symbols indicate binding; minus symbols indicate no binding. The horizontal solid line indicates the region included in each fusion protein. The shaded vertical bars indicate the two RNA binding regions defined from this analysis, and the amino acid sequence of each region is shown beneath the schematic figure. Arginine residues are indicated in bold type. (B) Amino acid sequence of the N-terminal 434 amino acids of SU(S). The amino acids deleted in the SU(S) $\triangle$ ARM mutants are shown in bold type. The two zinc binding motifs are underlined, and the cysteine (C) and histidine $(\mathrm{H})$ residues that are characteristic of this motif are shown in bold type.

(1). SU(S) was detected using a 1:400 dilution of affinity-purified polyclonal antibody, directed against SU(S) amino acids 648 to 808 (45), and a 1:50 dilution of goat anti-rabbit antibody conjugated with rhodamine as primary and secondary antibodies, respectively. HRP36 was detected using a 1:600 dilution of mouse monoclonal antibody 5cA5 (a gift from Gideon Dreyfuss) and a 1:50 dilution of goat anti-mouse secondary antibody conjugated with fluorescein isothiocyanate. Samples were examined by confocal microscopy. In double-labeling experiments, individual channel images were pseudocolored and combined using Photoshop software. For the whole mounts, salivary glands were fixed in $4.7 \%$ formaldehyde for $5 \mathrm{~min}$, washed with phosphate-buffered saline, and immunostained for SU(S) in essentially the same way as the squashes except that the incubation with primary antibody was longer (overnight instead of $4 \mathrm{~h}$ ), and a lower dilution (1:500) of the secondary antibody was used. The wild-type larvae were from strain Oregon R. The $s u(s)$ null mutant stock was $s u(s)^{R 39} \operatorname{ras}^{k}$. Larvae expressing the $s u(s)$ transgenes were from a $s u(s)^{R 39} \mathrm{ras} v^{k}$ stock with a recombinant third chromosome carrying both the $h s-G A L 4$ driver and a $s u(s)$ transgene. The transgenic stocks also contain the third chromosome balancer TM2; thus, larvae were either homozygous or heterozygous for the GAL4 driver and the UAS (upstream activation sequence)-su(s) transgene.

\section{RESULTS}

Two ARMs mediate the specific RNA binding activity of SU(S) in vitro. The amino acids responsible for the highaffinity RNA binding map to the N-terminal 360 amino acids of $\mathrm{SU}(\mathrm{S})$ (45). To define the RNA binding domain more precisely, we expressed cDNA fragments encoding various portions of this region in Escherichia coli as MBP fusions (see Materials and Methods). We then measured RNA binding activity of the affinity-purified fusion proteins using radioactively labeled 473-nucleotide (nt) ftz RNA as the substrate in either nitrocellulose filter binding or blot overlay binding assays as described previously (45) (Fig. 1A). These experiments 
A

8-5 5'- GAGCUGCAGACAACCAACCAGUCUCAGUAGUCAUUGGUGCACCUAAGAAACCUCGAGAC -3"

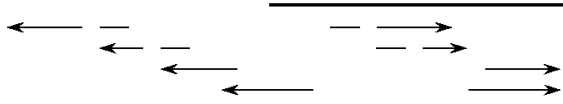

8-32 $5^{\prime}-$ GAGCUC
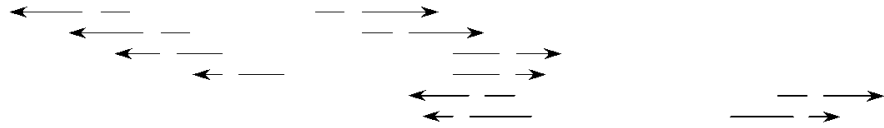

8-40
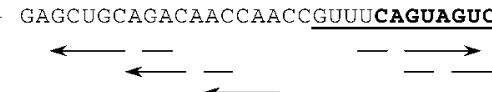

8-10

5'- GAgCUGCA

$$
\longleftarrow-
$$

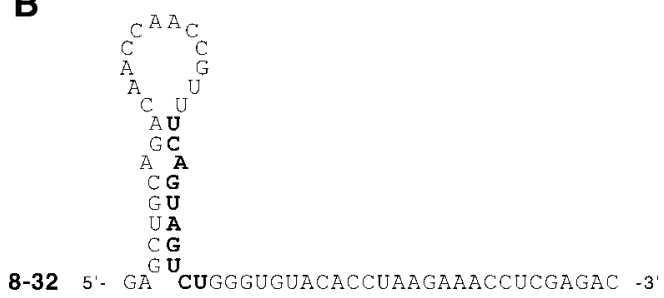

8-32 5 - $G \AA^{G}$

B
C

\begin{tabular}{|c|c|c|}
\multicolumn{3}{c}{$\mathrm{K}_{\mathrm{d}}(\mathrm{nM})$} \\
\hline wt & \multicolumn{1}{c|}{$\Delta \mathrm{ARM} 1$} & $\Delta \mathrm{ARM} 2$ \\
4.4 & 44 & 5.9
\end{tabular}

4.3

96

FIG. 2. SELEX RNAs used in the RNA binding assays. (A) Complete nucleotide sequences of RNAs were isolated as high-affinity substrates for SU(S) from a pool of 59-nt RNAs with random sequences in the central 20 positions (round 0) after eight rounds of SELEX (45). The arrows underneath each sequence define regions of potential structures as defined by the GCG Stemloop software. The randomized region of each RNA is defined by underlining. The SELEX consensus sequence is shown in bold type. The consensus RNAs are 8-5, 8-32, and 8-40; the nonconsensus RNAs are 8-10, 8-27, and 8-28. (B) Consensus RNA 8-32 with its SELEX consensus sequence paired in stem-loop structure. The consensus sequence is shown in bold type. (C) RNA binding activities of the MBP-SU(S) fusion proteins measured in nitrocellulose filter binding experiments. $K_{d}$ s shown were determined from the experiments shown in Fig. 3 by using SigmaPlot and are the averages of two to four independent experiments. Under the conditions of these experiments, the $K_{d}$ is equal to the protein concentration that results in $50 \%$ of the maximal RNA binding. In reactions with very low levels of binding over the range of protein concentrations tested, a maximum binding of $60 \%$ was assumed in estimating the $K_{d}$.

defined two nonoverlapping RNA binding regions, amino acids 150 to 215 and amino acids 266 to 309 . Examination of the amino acid sequence revealed that each of these regions contains a high proportion of arginine residues (Fig. 1A). This suggested that the RNA binding activity of SU(S) might involve ARMs $(11,56)$. To determine whether the arginine-rich regions are required for the RNA binding activity of $\mathrm{SU}(\mathrm{S})$, PCR mutagenesis was used to create precise 25-amino-acid deletions of sequences encoding residues 151 to $176(\Delta \mathrm{ARM} 1)$ and 269 to 294 ( $\triangle$ ARM2) (Fig. 1B). The deletions were introduced into an $M B P$-su $(s)$ cDNA clone encoding the N-terminal 434 amino acids of SU(S), which also includes the two zinc binding motifs (Fig. 1B).

Nitrocellulose filter binding assays were used to measure the affinity of the $\mathrm{SU}(\mathrm{S}) \Delta \mathrm{ARM}$ fusion proteins for $\mathrm{ftz}$ RNA and several small RNAs that were previously isolated by SELEX (45). The small RNAs were isolated after eight rounds of SELEX as high-affinity SU(S) targets from a starting pool of 59-nt RNAs, randomized over the central 20 nucleotide positions and with invariant flanking sequences. Three of the RNAs tested were from the class of SELEX RNAs that contain a close match to the consensus sequence UCAGUAG UCU (consensus RNAs 8-5, 8-32, and 8-40 [Fig. 2A]). Each consensus RNA is capable of forming several possible stemloops similar in structure, typically containing a mismatched base pair in the stem (Fig. 2A). The SELEX consensus sequence is predicted to base pair with sequences near the $5^{\prime}$ end of the RNA (Fig. 2B). The three other SELEX RNAs tested 

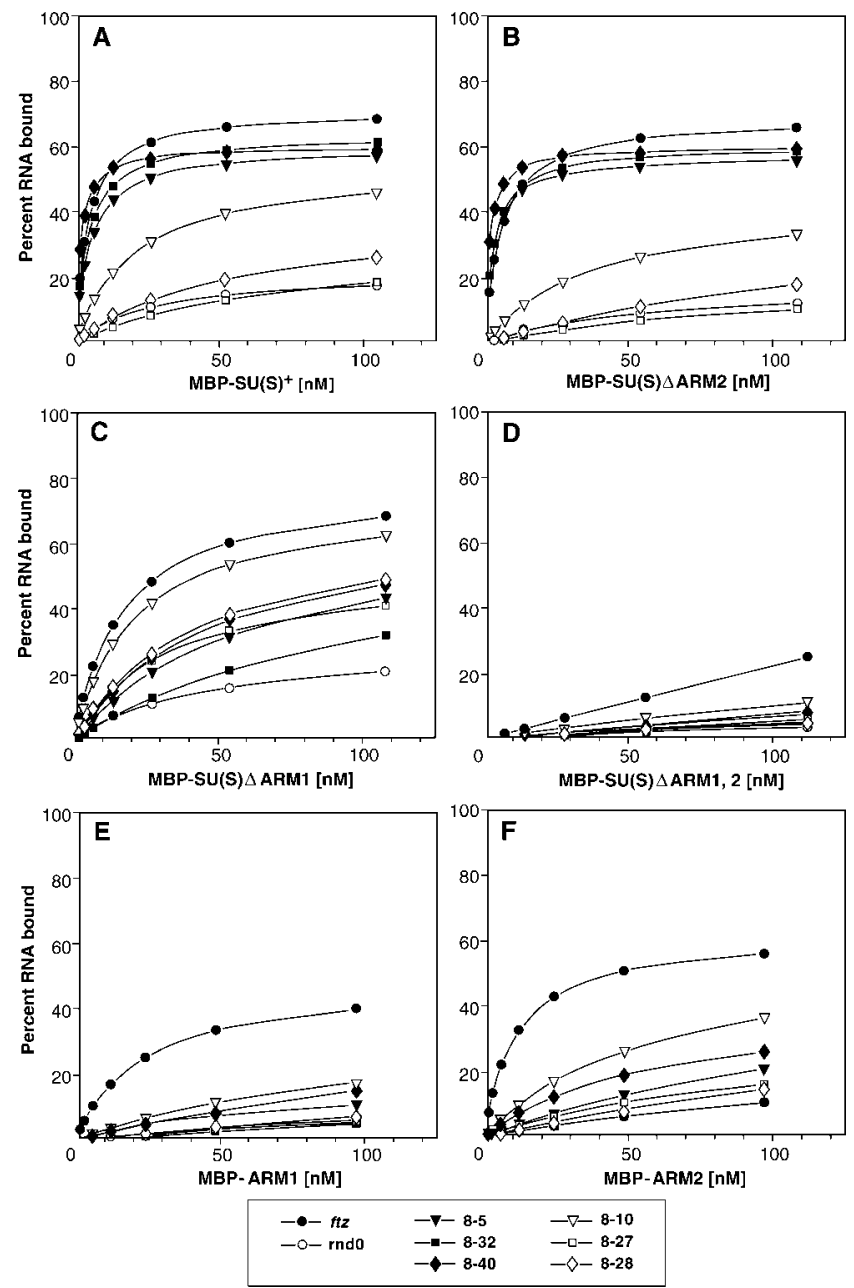

FIG. 3. RNA binding activity of MBP-SU(S) ARM deletion derivatives. The nitrocellulose filter binding assay was used to analyze the binding of affinitypurified preparations of MBP-SU(S) fusion proteins to various radioactively labeled RNAs. SELEX RNAs 8-5, 8-32, and 8-40 are consensus RNAs; SELEX RNAs 8-10, 8-27, and 8-28 are nonconsensus RNAs. Sequences of the SELEX round 8 RNAs are shown in Fig. 2. Each set of binding curves shows the activity of a different MBP-SU(S) fusion protein. (A) MBP-SU(S)wt, which contains the N-terminal 434 amino acids; (B to D) fusion proteins with deletions of ARM2, ARM1, and both ARM1 and ARM2, respectively; (E and F) derivatives with the 25 amino acids of ARM1 and ARM2, respectively, fused to MBP. Under the conditions of these experiments, the $K_{d}$ is equal to the protein concentration that results in $50 \%$ of maximal RNA binding.

were also isolated after eight rounds of SELEX but lack the consensus sequence (nonconsensus RNAs 8-10, 8-27, and 8-28 [Fig. 2A]) and are less capable of forming stem-loops than the consensus RNAs. The nonspecific RNA binding activity of the fusion proteins was measured using a pool of 59-nt RNAs that are randomized in the central 20 positions but have the same invariant flanking sequences as the SELEX round 8 RNAs.

Figures $2 \mathrm{C}$ and 3 illustrate the results of RNA binding experiments with these MBP-SU(S) fusion proteins. Whereas full-length recombinant $\mathrm{SU}(\mathrm{S})$ purified from baculovirus bound $f t z$ and all six SELEX round 8 RNAs with similar, high affinities (apparent $K_{d}=2$ to $9 \mathrm{nM}$ ) (45), the binding properties of the MBP-SU(S) fusion proteins were more complex. The affinity of the wild-type fusion protein [MBP-SU(S)wt] for $f t z$ and the three consensus RNAs (apparent $K_{d}=4$ to $5 \mathrm{nM}$ ) was 8- to 22-fold higher than its affinity for the nonconsensus
RNAs. Likewise, the fusion protein lacking ARM2 [MBP$\mathrm{SU}(\mathrm{S}) \Delta \mathrm{ARM} 2]$ bound consensus RNAs with apparent $K_{d} \mathrm{~s}$ of 4.3 to $5.9 \mathrm{nM}$ and nonconsensus RNAs with 15- to 50-foldlower affinity. On the other hand, the derivative lacking ARM1 [MBP-SU(S) $\Delta$ ARM1] exhibited a 10- to 20 -fold-lower affinity for consensus RNAs (apparent $K_{d}=44$ to $96 \mathrm{nM}$ ) than MBPSU(S)wt, although it bound $\mathrm{ftz}$ and nonconsensus RNAs with $K_{d}$ s ranging between 12 and $35 \mathrm{nM}$. The affinity of each of the MBP-SU(S) proteins for the randomized RNA pool was greater than $200 \mathrm{nM}$, and the derivative that lacks both ARMs $[\mathrm{MBP}-\mathrm{SU}(\mathrm{S}) \Delta \mathrm{ARM} 1,2]$ did not bind to any of the RNAs tested.

To determine whether either of the arginine-rich regions is sufficient for RNA binding, we generated MBP fusion proteins that contained only the 25 -amino-acid arginine-rich segments, ARM1 or ARM2, that were deleted in the experiments just described. MBP-ARM1 bound $f t z$ RNA with an apparent $K_{d}$ of approximately $40 \mathrm{nM}$ and the SELEX RNAs with $K_{d}$ s of 200 nM or greater (Fig. 3E). MBP-ARM2 bound $f t z$ with a $K_{d}$ of about $10 \mathrm{nM}$ and the SELEX RNAs with $K_{d} \mathrm{~s}$ of $60 \mathrm{nM}$ or greater (Fig. 3F). Thus, it appears that amino acids outside the regions defined by the ARM deletions contribute to the highaffinity binding of SU(S) to the SELEX RNAs. Furthermore, these results provide additional confirmation that the ARMdependent RNA binding activity is not due to electrostatic interactions.

Taken together, these experiments demonstrate that the amino acids within the regions defined by the ARM deletions mediate the in vitro RNA binding activity of SU(S). Whereas either ARM1 or ARM2 is sufficient for high-affinity binding to the larger ftz RNA, the ARM deletions differentially affect binding to the smaller SELEX RNAs. ARM1 is required for high-affinity binding to consensus RNAs, and ARM2 mediates binding to the nonconsensus RNAs. Since both the $\mathrm{SU}(\mathrm{S})$ zinc binding motifs are intact in the MBP-SU(S) $\Delta$ ARM1,2 fusion protein, which does not bind RNA, these motifs, by themselves, do not mediate RNA binding in vitro.

Overexpression of $\mathrm{SU}(\mathrm{S})$ can be lethal in vivo. Having established that the ARM deletions eliminate the in vitro RNA binding activity of $\mathrm{SU}(\mathrm{S})$, we wanted to assess the consequences of these alterations on $\mathrm{SU}(\mathrm{S})$ function in vivo. For this analysis, a wild-type full-length $s u(s) \mathrm{cDNA}$ and derivatives with the ARM deletions described above were constructed and introduced into flies by germ line transformation. A suitable $s u(s)$ promoter fragment capable of driving expression of a $s u(s)$ cDNA had not been defined. Therefore, we ligated the $s u(s)$ coding region to a promoter fragment containing UASs that are responsive to the transcriptional activator GAL4 (9). Transformants were isolated under conditions where the $U A S$ $s u(s)$ transgenes were transcriptionally inactive. Subsequently, ectopic expression of the transgenes was activated by performing a genetic cross to introduce a GAL4 transgene (GAL4 driver).

Because initial experiments indicated that ubiquitous expression of a wild-type $s u(s)$ transgene was lethal (data not shown), we examined the viability of flies expressing the $U A S$ $s u(s) w t$ transgene under the control of six different $G A L 4$ drivers (Table 1). This analysis was performed in the background of wild-type endogenous $s u(s)$. Analysis of the progeny recovered from these crosses demonstrated that different ectopic $\mathrm{SU}(\mathrm{S})$ expression patterns are lethal to variable degrees (Table $1)$. No progeny that carried both $U A S$-su(s)wt and the ubiquitously expressed $e 22 c-G A L 4$ driver were recovered. The viability of $U A S$-su(s)wt transformants containing T80-GAL4, which is ubiquitously expressed in imaginal discs, varied widely, with no T80-GAL4/UAS-su(s)wt progeny being recovered in 
TABLE 1. Viability of flies ectopically expressing $U A S$-su(s)wt under control of different $G A L 4$ drivers $^{a}$

\begin{tabular}{|c|c|c|c|c|c|}
\hline \multirow{2}{*}{ Line } & \multicolumn{2}{|c|}{ GAL4 } & \multirow{2}{*}{$\begin{array}{l}\text { No. of } G A L 4 / U A S- \\
s u(s) w t \text { lines tested }\end{array}$} & \multicolumn{2}{|c|}{$\%$ Viability } \\
\hline & Driver & $\begin{array}{l}\text { Expression } \\
\text { pattern }\end{array}$ & & Mean & Range \\
\hline $\mathrm{e} 22 \mathrm{c}$ & $e 22 c-G A L 4$ & Ubiquitous & 13 & 0 & 0 \\
\hline 2023 & sev-GAL4 & Restricted & 15 & 82 & $38-96$ \\
\hline $1799^{b}$ & $h s-G A L 4$ & Restricted & 5 & 100 & 100 \\
\hline 1878 & $T 80-G A L 4$ & Ubiquitous & 10 & 10 & $0-90$ \\
\hline 1774 & $69 B-G A L 4$ & Restricted & 14 & 32 & $0-100$ \\
\hline 1795 & $30 A-G A L 4$ & Restricted & 6 & 91 & $76-10$ \\
\hline
\end{tabular}

${ }^{a}$ Transformant lines, homozygous for a $U A S$-su(s)wt transgene, were crossed to $G A L 4$ driver stocks, and the progeny were reared at $25^{\circ} \mathrm{C}$. Multiple transformant lines were tested, and a single vial cross was set up for each transformant line. Viability was determined by calculating the percentage of progeny recovered that carried both transgenes relative to the expected number. Expression of the different GAL4 drivers (Bloomington Stock Center designations) has been characterized primarily in embryos and larval imaginal discs. The terms "ubiquitous" and "restricted" refer to the GAL4 expression pattern at the developmental stages or in tissues where it has been examined.

${ }^{b}$ This cross was performed without heat shock induction. The 1799 stock was homozygous for the $h s$-GAL4 driver, whereas the other GAL4 driver stocks were heterozygous with a balancer chromosome. Thus, this cross lacks a control group of siblings, and the $100 \%$ value in this case is an estimate of viability (see Materials and Methods).

more than half of the transformant lines tested (data not shown). The variation in the severity of the viability defect most likely reflects position-dependent differences in the expression levels of the $U A S$-su(s)wt transgene, presumably with higher levels of expression producing more pronounced effects. In contrast to the results obtained with ubiquitously expressed $G A L 4$ drivers, flies carrying $h s-G A L 4$ and $U A S$-su(s) were recovered at the usual frequency when reared in the absence of heat shock. The other GAL4 drivers (sev-GAL4, 69B-GAL4, and $30 A-G A L 4$ ), which generate restricted GAL4 expression patterns, produced relatively modest effects on viability. Thus, this analysis clearly indicates that overexpression of SU(S) is lethal. Analysis of survival at different developmental stages did not reveal a clear-cut lethal period; however, all of the developing flies died prior to pupation (data not shown).

We also examined the viability of flies expressing $U A S$ $s u(s) \triangle A R M$ single- and double-deletion mutant transgenes. As was seen with the wild-type $s u(s)$ transgene, no e22c-GAL4/ $U A S$-su(s) $\triangle A R M$ progeny were recovered with any of the derivatives tested (data not shown). Thus, the lethality caused by ubiquitous, high expression depends on a region of SU(S) other than, or in addition to, the ARMs. The viability of flies carrying the wild-type and ARM deletion mutants was also examined in the background of the sev-GAL4 driver. Expression of the sev-GAL4 transgene is controlled by a hybrid promoter, consisting of the hsp70 TATA box and the sevenless enhancer. This promoter directs $G A L 4$ expression primarily in eye discs (47). Examination of expression of a $U A S$-lacZ reporter gene under control of sev-GAL4 showed that this driver directs a low level of expression of a $U A S$ promoter in other larval tissues as well (our unpublished observations). Because the viability defects produced by this driver are relatively subtle, multiple transformant lines were analyzed for each $U A S$ $s u(s)$ transgene. Furthermore, to distinguish defects related to $U A S$-su(s) expression from those caused by disruption of a gene at the site of the transgene insertion, parallel experiments were performed both at 25 and $18^{\circ} \mathrm{C}$. Because GAL4 is less active at lower temperatures, viability defects related to the level of ectopically expressed SU(S) are expected to be more severe at 25 than $18^{\circ} \mathrm{C}(9)$, whereas defects related to gene
TABLE 2. Viability of flies expressing $U A S$-su(s) $\triangle A R M$ derivatives ${ }^{a}$

\begin{tabular}{|c|c|c|c|c|c|}
\hline \multirow{3}{*}{$\begin{array}{c}s u(s) \\
\text { transgene }\end{array}$} & \multirow{3}{*}{$\begin{array}{l}\text { Transformant } \\
\text { line }\end{array}$} & \multicolumn{4}{|c|}{ sev-GAL4/UAS-su(s) progeny } \\
\hline & & \multicolumn{2}{|c|}{$\%$ of total } & \multicolumn{2}{|c|}{$\%$ Viability } \\
\hline & & $25^{\circ} \mathrm{C}$ & $18^{\circ} \mathrm{C}$ & $25^{\circ} \mathrm{C}$ & $18^{\circ} \mathrm{C}$ \\
\hline None & NA & $55.9(3)$ & $55.4(2)$ & 100 & 100 \\
\hline \multirow[t]{3}{*}{$w t$} & $18 \mathrm{~A}$ & $33.1(12)^{*}$ & $46.4(3)^{* * *}$ & 59 & 84 \\
\hline & $25 \mathrm{~A}$ & $20.9(3)^{* * * *}$ & $30.8(4)^{* * *}$ & 37 & 56 \\
\hline & $27 \mathrm{~A}$ & $10.7(8)^{* * *}$ & $30.5(5)^{* *}$ & 19 & 55 \\
\hline \multirow[t]{3}{*}{$\triangle A R M 1$} & $15 \mathrm{~B}$ & $48.4(5)^{*}$ & $53.8(1)^{*}$ & 87 & 97 \\
\hline & $19 \mathrm{C}$ & $52.6(1)^{*}$ & $52.5(4)^{*}$ & 94 & 95 \\
\hline & $28 \mathrm{~A}$ & $35.6(2)^{* * *}$ & $34.5(4)^{* * *}$ & 64 & 62 \\
\hline \multirow[t]{3}{*}{$\triangle A R M 2$} & $1 \mathrm{~A}$ & $33.0(2)^{* * *}$ & $27.2(5)^{* * *}$ & 59 & 49 \\
\hline & $4 \mathrm{E}$ & $50.1(3)^{*}$ & $27.2(7)^{* *}$ & 90 & 49 \\
\hline & $40 \mathrm{C}$ & $39.0(10)^{*}$ & $31.2(3)^{* * * *}$ & 70 & 56 \\
\hline \multirow[t]{3}{*}{$\triangle A R M 1,2$} & 9B & $49.4(5)^{*}$ & $49.4(6)^{*}$ & 88 & 89 \\
\hline & $10 \mathrm{C}$ & $54.5(3) *$ & $56.7(2)^{*}$ & 97 & 102 \\
\hline & $17 \mathrm{~A}$ & $45.2(2)^{* *}$ & $46.0(7)^{*}$ & 81 & 83 \\
\hline
\end{tabular}

${ }^{a}$ Females homozygous for a $U A S$-su(s) transgene on the second chromosome were crossed with heterozygous males carrying a second chromosome insertion of the sev-GAL4 transgene and a second chromosome balancer marked with $C y$. The vials were incubated at either 25 or $18^{\circ} \mathrm{C}$. Control crosses between $y w$ females from the injection stock, lacking a $U A S$-su(s) transgene, and sev$G A L 4 / C y$ males were performed in parallel. The percentage of sev-GAL4/UAS$s u(s)$ progeny was determined by calculating the percentage of progeny with straight wings. Viability was measured by determining the percentage of straightwinged progeny obtained from the experimental versus the control cross. Standard deviations are shown in parentheses. $P$ values, calculated by Student's $t$ test, indicate the probability that the number obtained from each experimental cross is the same as number from the control cross: $*, P>0.05$ (not significantly different from the control); **, $0.05>P<0.01$; ***, $0.01>P<0.001$; ****, $P<$ 0.001. NA, not applicable.

disruption at the site of the transgene insertion are unlikely to be affected by temperature.

In these experiments, differences were observed in the viability of flies expressing the $s u(s) w t$ and various $s u(s) \Delta A R M$ transgenes (Table 2). Flies expressing $s u(s) w t$ were recovered at 19 to $59 \%$ of the expected frequency at $25^{\circ} \mathrm{C}$ and at higher frequencies at $18^{\circ} \mathrm{C}$. Thus, consistent with the analysis described earlier, expression of the wild-type transgene reduces viability. On the other hand, two of the three transformant lines expressing $s u(s) \triangle A R M 1$ and all three lines expressing $s u(s) \triangle A R M 1,2$ were recovered at close to the expected frequencies at both temperatures, indicating that these transgenes do not negatively affect viability. The viability defect observed in one $U A S$-su(s) $\triangle A R M 1$ transformant line (28A [Table 2]) appeared to be related to disruption of a gene at the site of the $U A S$-su(s) transgene insertion because flies expressing the transgene were recovered at similar, low frequencies at both temperatures. Two of the three lines expressing $s u(s) \triangle A R M 2$ were recovered at frequencies that were not significantly different from the wild-type level at $25^{\circ} \mathrm{C}$. However, all three $s u(s) \triangle A R M 2$-expressing lines were recovered at a lower than expected frequency at $18^{\circ} \mathrm{C}$. Taken together, these results indicate that the ARMs mediate one, but not the only, component of the lethal effect of overexpressing SU(S). Furthermore, the lower viability of $s u(s) \triangle A R M 2$-expressing flies at $18^{\circ} \mathrm{C}$, the temperature at which less protein should be produced, suggests that deletion of ARM2 increases the detrimental activity of $\mathrm{SU}(\mathrm{S})$ at $18^{\circ} \mathrm{C}$.

Examination of the eye color of flies carrying the hypomorphic $s u(s)^{51 c 15}$ allele, the suppressible $v^{k}$ allele, the $U A S$ $s u(s) w t$ cDNA transgene, and the $h s-G A L 4$ driver revealed that the $U A S$-su(s)wt cDNA transgene did not provide $s u(s)$ function sufficient to rescue the $v$ eye color phenotype at $25^{\circ} \mathrm{C}$ (data 

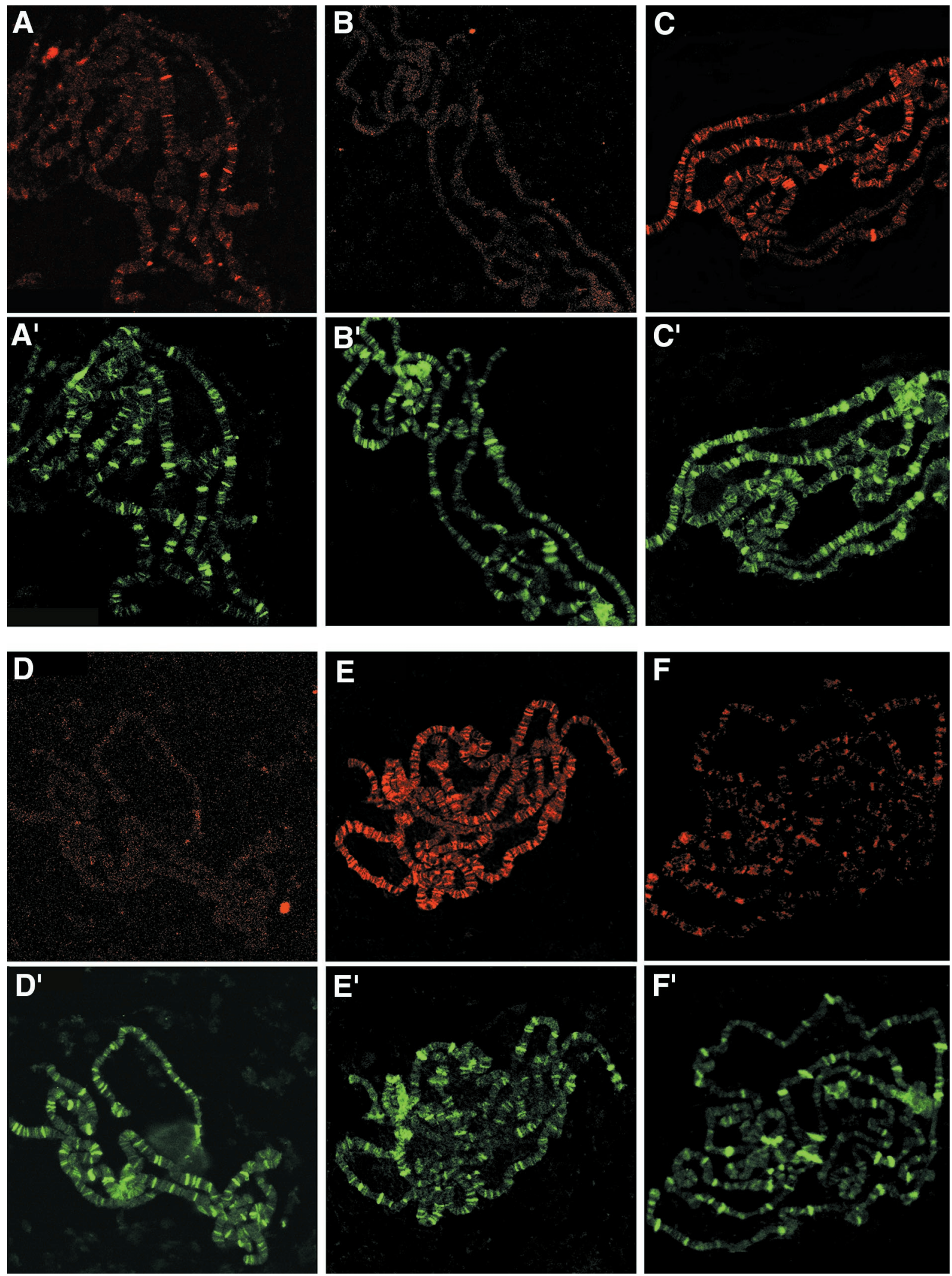

FIG. 4. Immunolocalization of SU(S) ARM mutant derivatives on third-instar larval salivary gland polytene chromosomes. Shown are confocal images of chromosome squashes double labeled by indirect immunofluorescence with antibodies that recognize SU(S) and the positive control HRP36. The pseudocolored images indicate $\mathrm{SU}(\mathrm{S})$ in red (A to $\mathrm{F}$ ) and HRP36 in green $\left(\mathrm{A}^{\prime}\right.$ to $\left.\mathrm{F}^{\prime}\right)$. HRP36 is found at a much larger number of bands than endogenous SU(S), and there is little overlap between strong HRP36 sites and strong $\mathrm{SU}(\mathrm{S})$ sites. $\left(\mathrm{A}\right.$ and $\left.\mathrm{A}^{\prime}\right) s u(s)^{+} ;\left(\mathrm{B}^{2}\right.$ and $\left.\mathrm{B}^{\prime}\right) s u(s)^{R 39}$ null mutant. The remaining images were prepared from larvae grown at room temperature, expressing an SU(S) cDNA transgene under control of the $h s-G A L 4$ driver in $s u(s)$ null mutant background: (C and $\left.\mathrm{C}^{\prime}\right) \mathrm{SU}(\mathrm{S}) \mathrm{wt}$; (D and $\left.\mathrm{D}^{\prime}\right)$ SU(S) $\Delta$ ARM1; (E and $\left.E^{\prime}\right)$ SU(S) $\Delta$ ARM2; (F and $\mathrm{F}^{\prime}$ ) SU(S) $\Delta$ ARM1,2. 
not shown). At higher temperatures, heat shock-induced expression of $U A S$-su(s)wt was lethal. Other GAL4-driven $s u(s)$ expression patterns either did not rescue or gave ambiguous results. Thus, this expression system was unsuitable for determining whether the ARMs are required for the function of $\mathrm{SU}(\mathrm{S})$ in regulating expression of mutant $v$ alleles. These observations, together with the ectopic expression induced lethality, indicate that the normal regulatory activity of $\mathrm{SU}(\mathrm{S})$ is highly dependent on the level and pattern of $s u(s)$ expression.

ARM1 is required for the polytene chromosome association of SU(S). Endogenous SU(S) is found both in the extrachromosomal compartment of the nucleus and at discrete sites on larval salivary gland polytene chromosomes (45). When polytene chromosomes from wild-type flies are stained by indirect immunofluorescence with anti-SU(S) polyclonal antibodies, a strong signal is observed at fewer than 20 chromosomal sites whereas many other sites give a weak signal. Since SU(S) is an RNA binding protein, the chromosomal localization is likely to represent SU(S) binding to nascent RNA transcripts, although it is possible that $\mathrm{SU}(\mathrm{S})$ also interacts with one or more chromatin-associated components. To test whether the ARM deletions affect the chromosomal association of SU(S), we used immunofluorescence to examine polytene chromosomes from larvae expressing wild-type and ARM deletion $U A S$-su(s) transgene derivatives under control of the $h s-G A L 4$ driver, which is expressed in salivary glands even in the absence of heat shock (Fig. 4). This analysis was performed in the background of an endogenous $s u(s)^{R 39}$ null mutant, which gives no immunofluorescence signal with the anti-SU(S) antibodies used (Fig. 4B). Polytene chromosomes were simultaneously labeled with polyclonal anti-SU(S) polyclonal antibodies and with a monoclonal antibody (5cA5) that recognizes HRP36, one of the abundant hnRNP proteins in Drosophila. In this experiment, anti-HRP36 was used solely as a positive control for the immunostaining procedure.

A larger number of chromosomal sites stained strongly with the anti-SU(S) antibodies in chromosome squashes prepared from larvae expressing SU(S)wt (Fig. 4C) and SU(S) $\Delta$ ARM2 (Fig. 4E) than in larvae lacking the transgene (Fig. 4A). The stronger signal at least in part reflects the higher level of SU(S) produced by the transgenes (see below). In contrast, no signal was observed when chromosomes expressing SU(S)DARM1 were stained with anti-SU(S) antibodies (Fig. 4D). Results obtained with chromosomes from transformants expressing the double-deletion derivative $\mathrm{SU}(\mathrm{S}) \Delta \mathrm{ARM} 1,2$ were somewhat variable. In some experiments no chromosomal association of $\mathrm{SU}(\mathrm{S}) \Delta \mathrm{ARM} 1,2$ was detected (data not shown), whereas in other experiments weak staining was observed. As described below, $\mathrm{SU}(\mathrm{S}) \Delta \mathrm{ARM} 1,2$ is expressed at very high levels in comparison to the other SU(S) derivatives. Thus, it is possible that $\mathrm{SU}(\mathrm{S})$ interacts weakly with polytene chromosomes independent of its RNA binding motifs.

One possible explanation for the failure of SU(S) $\Delta A R M 1$ and $\mathrm{SU}(\mathrm{S}) \Delta \mathrm{ARM} 1,2$ to associate with polytene chromosomes might be that the ARM1 deletion blocks entry of these proteins into the nucleus. Immunofluorescence labeling of whole salivary gland cells demonstrated that each of the SU(S) derivatives accumulates in the nucleus as expected (Fig. 5). Another possibility is that the proteins are unstable. However, Western blot analysis (data not shown; see below) indicates that the proteins produced by the transgenes accumulate at higher levels than endogenous SU(S). Based on these results, we conclude that ARM1, which promotes binding to SELEX consensus RNAs in vitro, is required for the stable association of SU(S) with polytene chromosomes in vivo and that ARM2 alone is neither sufficient nor required for this interaction.
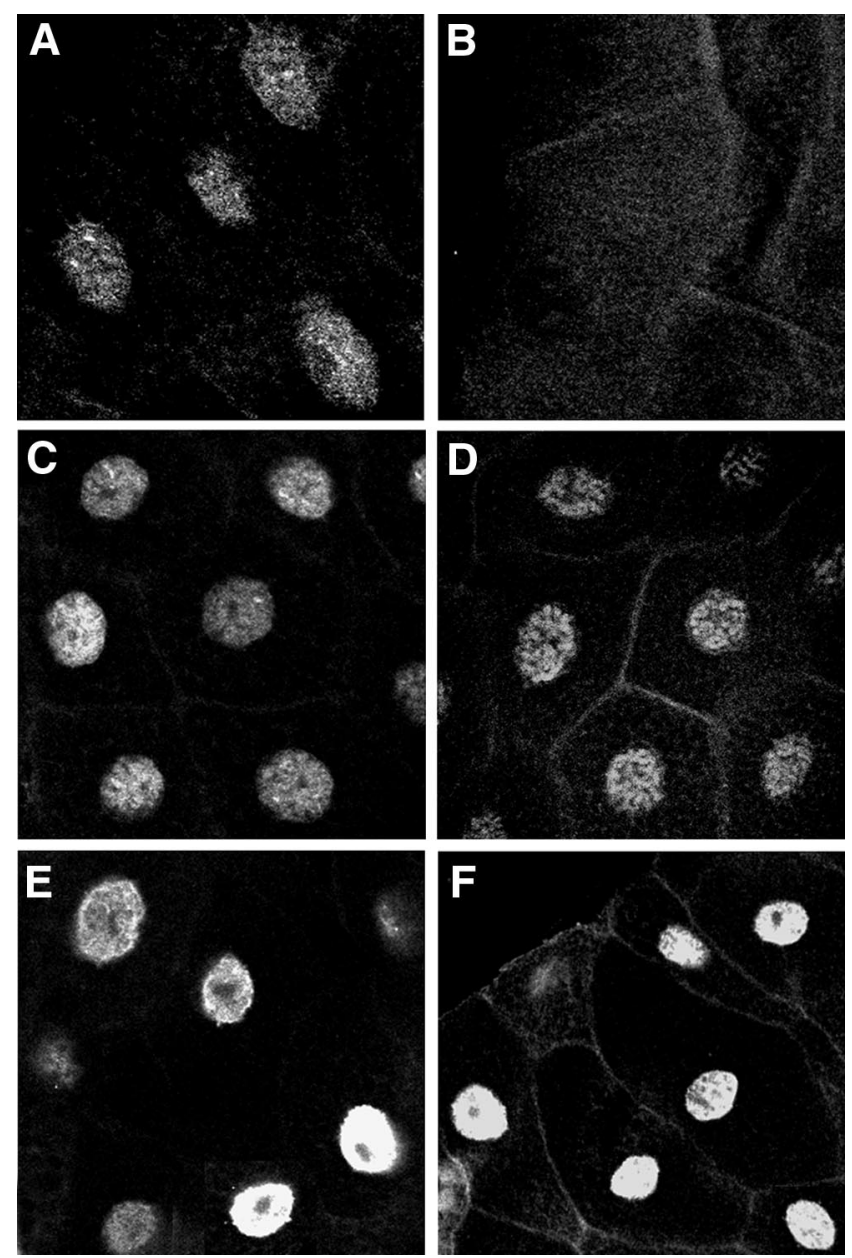

FIG. 5. Nuclear localization of SU(S)ARM derivatives in salivary gland cells Shown are confocal images of whole mounts of third-instar larval salivary glands labeled by indirect immunofluorescence with a polyclonal anti-SU(S) antibody. Like endogenous SU(S), the four SU(S) derivatives localize in the nucleus. (A) $s u(s)^{+}$; (B) $s u(s)$ null mutant. (C to F) Images prepared from larvae expressing various $\mathrm{SU}(\mathrm{S})$ transgenes under control of the $h s-G A L 4$ driver in $s u(s)$ null mutant background: (C) SU(S)wt; (D) SU(S) $\Delta$ ARM1; (E) SU(S) $\Delta$ ARM2; (F) $\mathrm{SU}(\mathrm{S}) \Delta \mathrm{ARM} 1,2$.

$\mathrm{SU}(\mathrm{S}) \mathrm{wt}$ represses RNA accumulation from the $s u(s)$ cDNA transgenes. We used Western blots to compare the levels of $\mathrm{SU}(\mathrm{S})$ produced by the different transgenes. Quite unexpectedly, we found that SU(S) $\triangle \mathrm{ARM} 1,2$ accumulates at a much higher level than SU(S)wt (Fig. 6A). This higher level of mutant protein accumulation was observed with more than 10 different transformant lines (data not shown) and with three different GAL4 drivers (data not shown). Thus, the difference is not likely to be related to position-dependent variation in transcription of the transgene or tissue-specific effects. The accumulation level of SU(S) derivatives with single ARM deletions varied between transformant lines. In some transformants, SU(S) $\triangle$ ARM1 or SU(S) $\triangle A R M 2$ accumulated at similar levels as SU(S)wt. In other transformants, the single deletion derivatives accumulated at levels intermediate levels, i.e., higher than SU(S)wt but substantially lower than SU(S) $\Delta$ ARM1,2 (data not shown).

We performed Northern blot analysis on poly $(\mathrm{A})^{+}$mRNA isolated from adult flies carrying the wild-type and double- 
A

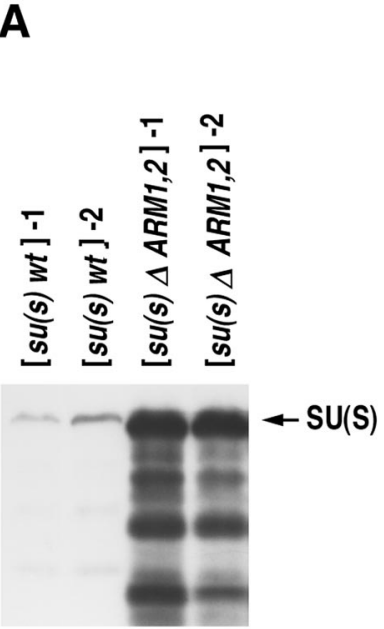

B

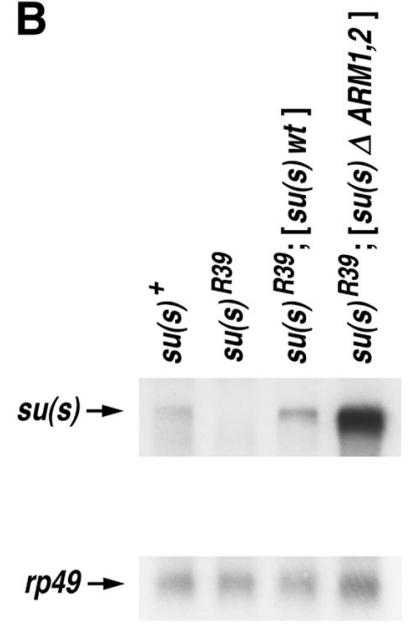

FIG. 6. Levels of $s u(s) w t$ and $s u(s) \Delta A R M 1,2$ expression. (A) Western blot of total protein $(200 \mu \mathrm{g}$ per lane) extracted from balanced stocks with a recombinant third chromosome carrying both a $U A S$-su(s) transgene and the hs-GAL4 driver. The blot was probed with an anti-SU(S) polyclonal antibody. (B) Northern blot of polyadenylated adult RNA ( $2 \mu \mathrm{g}$ per lane) isolated from the same flies as in panel A probed with $s u(s)$ and $r p 49$ cloned sequences.

mutant $s u(s)$ transgenes in the background of the $s u(s)^{R 39}$ allele (Fig. 6B). This analysis showed that the difference also occurs at the RNA level; i.e., $s u(s) \triangle A R M 1,2$ transcript accumulates at a higher level than $s u(s) w t$ mRNA transcript. We reasoned that the difference in RNA levels could be due to either nucleotide sequence differences between the wild-type and mutant RNAs or a difference in the ability of the wild-type and mutant $\mathrm{SU}(\mathrm{S})$ proteins to regulate the amount of RNA generated from the transgenes. To distinguish between these possibilities, we designed a cis-trans test and performed a cross to introduce both transgenes into the same cells. If the mutant RNA accumulates at a higher level because it is inherently more stable (a cis effect), then the difference in RNA levels will also occur when both transgenes are expressed in the same cells. On the other hand, if $\mathrm{SU}(\mathrm{S})$ regulates accumulation of these RNAs (a trans effect), then the $s u(s) w t$ and $s u(s) \Delta A R M 1,2$ RNAs will be found at similar levels in cells that express both proteins. In the latter case, the level of the two RNAs would depend on the degree to which $\mathrm{SU}(\mathrm{S}) \Delta \mathrm{ARM} 1,2$ interferes with the activity of SU(S)wt.

We performed RNase protection analysis to compare the levels of the $s u(s) w t$ and $s u(s) \Delta A R M 1,2$ RNAs in flies carrying one copy of either the wt or mutant transgene and flies carrying one copy of both transgenes (Fig. 7). This analysis was performed in the background of the $s u(s)^{R 39}$ null mutant. To distinguish between the $s u(s) w t$ and $s u(s) \Delta A R M 1,2$ transcripts, we used a wild-type, antisense $s u(s)$ RNA probe that spans the ARM coding region. After hybridization and RNase treatment, su(s)wt and $s u(s) \Delta A R M 1,2$ transcripts generate 394- and 262-nt protected fragments, respectively. As shown in Fig. 7, the level of $s u(s)$ transcript in RNA prepared from flies carrying only the mutant transgene was fivefold higher than the level observed in flies that were carrying only the $s u(s) w t$ transgene. In contrast, in RNA prepared from flies expressing both the wild-type and $\Delta$ ARM1,2 transgenes, both $s u(s)$ RNA types accumulated at a similar level. This demonstrates that SU(S) protein regulates accumulation of RNA from the $U A S$-su(s) cDNA transgenes and that the ARMs mediate this regulation. In flies expressing both transgenes, the level of $s u(s) w t$ RNA
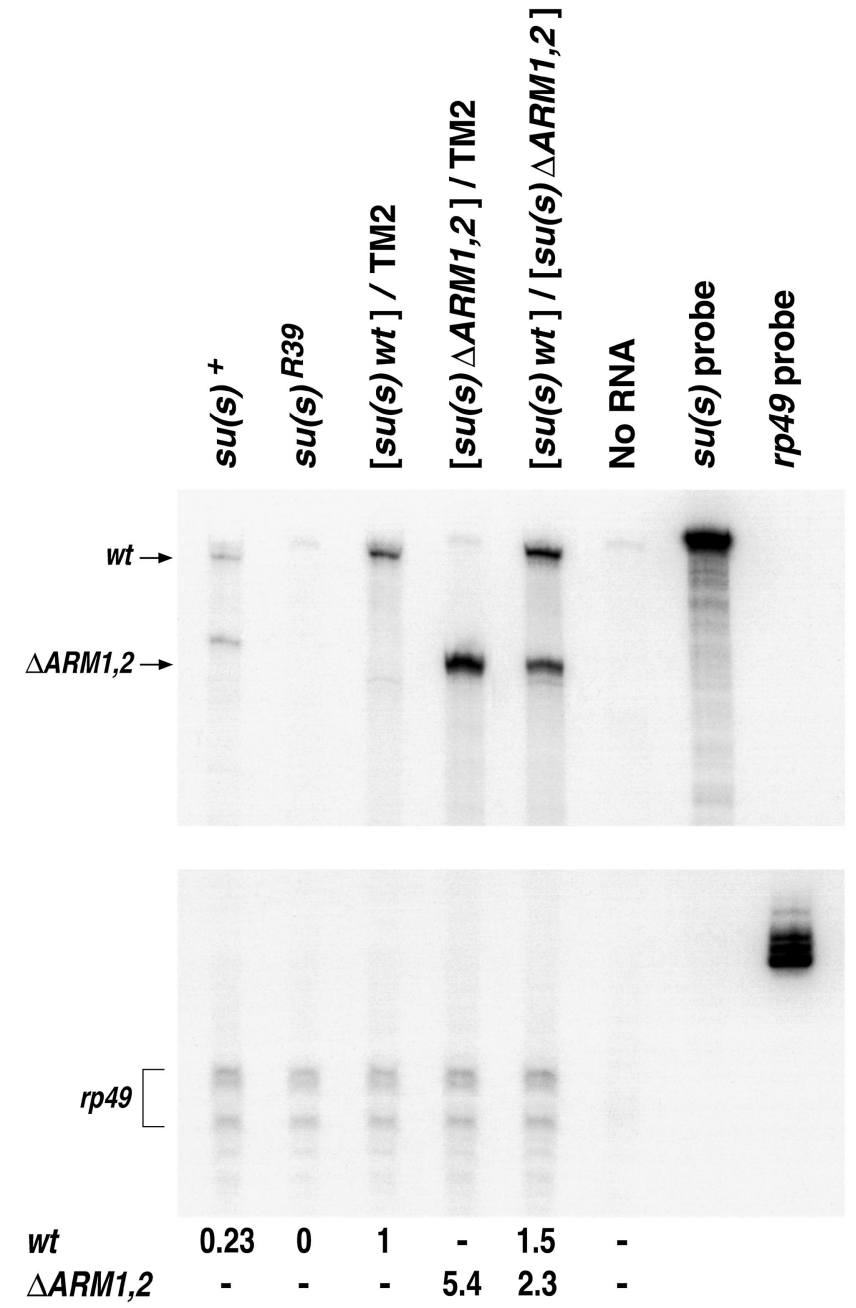

FIG. 7. RNase protection analysis of $s u(s) w t$ and $s u(s) \Delta A R M 1,2$ RNA levels. Total RNA was isolated from adult flies reared at $25^{\circ} \mathrm{C}$. Flies with one copy of a transgene contained the third chromosome balancer TM2 and a recombinant third chromosome carrying a $U A S$-su(s) transgene and the $h s-G A L 4$ driver. Flies with both transgenes contained a wild-type transgene on one of the third chromosomes and a mutant transgene on the other. The transgenic flies also carry the null $s u(s)^{R 39}$ allele on the $\mathrm{X}$ chromosome and thus produce no endogenous $s u(s)$ protein or mRNA; $20 \mu \mathrm{g}$ of total RNA was used in each reaction. The 447-nt hybridization probe in this experiment was prepared from a wild-type $s u(s)$ cDNA clone and spans the region that encodes the ARMs (see Materials and Methods). The $s u(s) w t$ and $s u(s) \Delta A R M 1,2$ protected fragments are 394 and 262 nt, respectively. Indicated beneath the lanes are the relative RNA levels. The values shown are the average of three separate experiments performed with the same RNA preparations. The standard deviations were less than $10 \%$ of the values shown.

was 1.5-fold higher than the level of this RNA in flies carrying only the wild-type transgene. The level of $s u(s) \triangle A R M 1,2$ RNA was twofold lower in flies carrying both transgenes than in flies expressing only the $s u(s) \triangle A R M 1,2$ transgene. These intermediate levels suggest that both the wild-type and ARM deletion derivatives of $\mathrm{SU}(\mathrm{S})$ can influence RNA production from the transgenes and that there is not a clear dominance relationship between the wild-type and mutant forms of the protein.

In attempt to test whether $s u(s) \triangle A R M 1,2$ is capable of elevating the amount of RNA produced from endogenous $s u(s)$, we crossed the GAL4-driven $U A S$-su(s) $\triangle A R M 1,2$ transgene into the background of a wild-type endogenous $s u(s)$ allele and 
performed Northern analysis with a probe that could detect only the endogenous $s u(s)$ transcript. We observed no effect of the $s u(s) \triangle A R M 1,2$ transgene on the level of endogenous $s u(s)$ RNA (data not shown). This could indicate that SU(S) $\triangle A R M 1,2$ is not capable of affecting regulation of the endogenous $s u(s)^{+}$ gene. However, the absence of an effect might be because $\mathrm{SU}(\mathrm{S}) \triangle \mathrm{ARM} 1,2$ produced by the $G A L 4$-driven transgene is not expressed in the appropriate tissue or at the level needed to effect expression of endogenous $s u(s)$. Thus, no definitive conclusion could be drawn from this experiment.

\section{DISCUSSION}

We have shown that two ARMs mediate the in vitro RNA binding activity and in vivo function of SU(S). ARM1 is required for high-affinity binding of SU(S) to SELEX consensus RNAs, whereas ARM2 promotes binding at roughly a 10 -foldlower affinity to SELEX nonconsensus RNAs. The CCCH zinc binding motifs, located just downstream of the ARMs, are incapable of promoting stable RNA binding in vitro, although they may influence the stability of the SU(S)-RNA interaction in vivo. The SELEX consensus RNAs contains a close match to the sequence UCAGUAGUCU, flanked by GU-rich sequences. Previous in vitro RNA footprinting experiments showed that recombinant, baculovirus-expressed SU(S) interacts with nucleotides of the consensus and GU-rich regions (45). The SELEX consensus sequence is complementary to invariant sequences near the 5' end of the SELEX RNA. Thus, one explanation for the repeated isolation of RNAs containing this sequence is that it enables the RNA to fold into a hairpin structure recognized by $\mathrm{SU}(\mathrm{S})$, rather than representing a particular sequence that is bound by $\mathrm{SU}(\mathrm{S})$. However, the sequence composition of the stem-loop might be a factor in SU(S) binding. For example, as previously noted (45), the SELEX consensus sequence resembles the $5^{\prime}$ splice site consensus MAGGURAGU, where $\mathrm{M}$ denotes $\mathrm{C}$ or $\mathrm{A}, \mathrm{R}$ denotes $\mathrm{A}$ or $\mathrm{G}$, and the underlined $\mathrm{GU}$ is the invariant dinucleotide found at the $5^{\prime}$ boundary of the intron (44) and the sequence commonly found near the transcription initiation site (UCAGU) (14). Perhaps SU(S) binds to stem-loops in regions of a pre-mRNA that includes these sequences, i.e., near the cap site and/or 5' splice site. Additional work will be required to determine the relative importance of RNA sequence versus structure in the binding activity mediated by ARM1.

The ARMs of SU(S), particularly ARM1, exhibit the usual features that are characteristic of this class of RNA binding motif. ARM-RNA binding domains are typically short, i.e., 10to 20-amino-acid, arginine-rich regions that recognize particular structural features of RNA rather than a specific sequence (11). The most extensively studied ARM proteins, including N protein of bacteriophage lambda, Nun protein of bacteriophage HK022, and human immunodeficiency virus Tat and Rev, bind near the $5^{\prime}$ end of their target transcripts $(34,39,50$, $54,55)$ and regulate either transcription elongation or RNA export (17-19).

Previous work has shown that several $s u(s)$-suppressible alleles have antisense transposon insertions in the $5^{\prime}$ region of their genes that disrupt either the first exon or the first intron (20-22, 29). A higher level of RNA is produced by these mutant alleles in $s u(s)$ mutants than in $s u(s)^{+}$flies. In our earlier studies, we proposed that the regulation of RNA accumulation by $\mathrm{SU}(\mathrm{S})$ was at the level of RNA stability, because the effect was related to splicing complex assembly, which at the time was thought to occur posttranscriptionally. However, since transcription and RNA processing are coupled, it is possible that $\mathrm{SU}(\mathrm{S})$ binding to RNA affects transcription. For example, perhaps $\mathrm{SU}(\mathrm{S})$ binding stabilizes stem-loop structure in the $5^{\prime}$ region of the pre-mRNA, which, in turn, pauses the elongating transcription complex. Splicing complex assembly in the $5^{\prime}$ region of the pre-mRNA might release the paused RNA polymerase II just as ribosome binding to a nascent transcript releases the paused prokaryotic RNA polymerase to synchronize transcription and translation (13). Suppressible mutant alleles contain transposon insertions near their $5^{\prime}$ regions and thus lack normal splicing signals near the transcription start sites. Expression of these insertion mutant alleles would, thus, be irreversibly repressed by $\mathrm{SU}(\mathrm{S})$ binding. This type of role for $\mathrm{SU}(\mathrm{S})$ in regulating cotranscriptional splicing complex assembly is analogous to the proposed role of SPT5 and its homologues in repressing transcription elongation to couple capping to transcription $(23,53)$. Studies currently under way are designed to test whether $\mathrm{SU}(\mathrm{S})$ regulates transcription or RNA stability.

In this report, we have demonstrated that SU(S) negatively regulates production of transcripts from the $U A S$-su(s) cDNA transgenes. Thus, we have identified the first example of regulation by SU(S) that does not involve mutant transcripts with a transposon insertion. This effect cannot be explained in terms of our previous model that SU(S) binds cryptic splice sites to promote recognition of authentic splice sites because the only intron present in these constructions is a small simian virus 40 intron, which was introduced into the $3^{\prime}$ untranslated region during subcloning of the cDNA into the transformation vector (9). Like the mutant $v$ and $y$ alleles that are negatively regulated by $\mathrm{SU}(\mathrm{S})$, the first intron of the $s u(s)$ cDNA transgenes is a long distance, $5 \mathrm{~kb}$, downstream of the transcription start site. In most intron-containing pre-mRNAs, the first intron is located near the beginning of the transcribed region (41), and an intron in this position appears to be important for expression at a high level. Studies in a variety of different systems indicate that cDNA transgenes are expressed at lower levels than their genomic counterparts in vivo and that expression of a cDNA can be elevated by inclusion of an intron near the 5' end of the gene $(10,30,31,37,38,46)$. The magnitude of this effect varies, depending on sequences present in the RNA and the promoter that is used to direct transgene expression $(33,35)$. Furthermore, in a study that examined the factors that influence intron-dependent enhancement of gene expression, the strength of the $5^{\prime}$ splice site was found to be important (31). Likewise, we previously showed that improvement of a cryptic $5^{\prime}$ splice site near the beginning of a mutant $v$ transgene to a consensus site increased RNA production from a mutant $v$ transgene, without improving the splicing efficiency. In addition, SU(S) does not inhibit the production of RNA from the transgene with a consensus $5^{\prime}$ splice site near the beginning of the transcribed region but does limit production of RNA from a similar transgene that lacks a strong $5^{\prime}$ splice site in this region (21). In light of these observations, it seems plausible that $\mathrm{SU}(\mathrm{S})$ is a component of the intron-dependent gene expression pathway and that studies of SU(S) function will provide insights into the general mechanism that limits expression of cDNA transgenes and antisense RNAs in vivo. The $s u(s)$ gene is nonessential, although $s u(s)$ mutations impair viability and fertility to variable degrees (36). However, our finding that overexpression of $\mathrm{SU}(\mathrm{S})$ can be lethal suggests that SU(S) functions in an essential process and that the level of SU(S) in the nucleus is an important aspect of its regulatory activity. 


\section{ACKNOWLEDGMENTS}

We thank G. Dreyfuss for providing monoclonal antibody 5 cA5. We thank G. Maroni and M. Peifer for critical comments on the manuscript and R. Kole for a helpful discussion. We are grateful to S. Whitfield for assistance with the figures.

This work was supported by grants MCB-950631 and MCB-9808150 from the National Science Foundation.

\section{REFERENCES}

1. Ashburner, M. 1989. Drosophila: a laboratory manual. Cold Spring Harbor Laboratory Press, Cold Spring Harbor, N.Y.

2. Ausubel, F. M., R. Brent, R. E. Kingston, D. D. Moore, J. G. Seidman, J. A. Smith, and K. Struhl (ed.). 1995. Current protocols in molecular biology. John Wiley \& Sons, Inc., New York, N.Y.

3. Bai, C., and P. P. Tolias. 1996. Cleavage of RNA hairpins mediated by a developmentally regulated $\mathrm{CCCH}$ zinc finger protein. Mol. Cell. Biol. 16: 6661-6667.

4. Bai, C., and P. P. Tolias. 1998. Drosophila clipper/CPSF 30K is a posttranscriptionally regulated nuclear protein that binds RNA containing GC clusters. Nucleic Acids Res. 26:1597-1604.

5. Barabino, S. M., W. Hubner, A. Jenny, L. Minvielle-Sebastia, and W. Keller. 1997. The 30-kD subunit of mammalian cleavage and polyadenylation specificity factor and its yeast homolog are RNA-binding zinc finger proteins. Genes Dev. 11:1703-1716.

6. Batchelder, C., M. A. Dunn, B. Choy, Y. Suh, C. Cassie, E. Y. Shim, T. H. Shin, C. Mello, G. Seydoux, and T. K. Blackwell. 1999. Transcriptional repression by the Caenorhabditis elegans germ-line protein PIE-1. Genes Dev. 13:202-212.

7. Bentley, D. 1999. Coupling RNA polymerase II transcription with premRNA processing. Curr. Opin. Cell Biol. 11:347-351.

8. Beyer, A. L., and Y. N. Osheim. 1988. Splice site selection, rate of splicing, and alternative splicing on nascent transcripts. Genes Dev. 2:754-765.

9. Brand, A. H., A. S. Manoukian, and N. Perrimon. 1994. Ectopic expression in Drosophila. Methods Cell Biol. 44:635-654.

10. Buchman, A. R., and P. Berg. 1988. Comparison of intron-dependent and intron-independent gene expression. Mol. Cell. Biol. 8:4395-4405.

11. Burd, C. G., and G. Dreyfuss. 1994. Conserved structures and diversity of functions of RNA-binding proteins. Science 265:615-621.

12. Carballo, E., W. S. Lai, and P. J. Blackshear. 1998. Feedback inhibition of macrophage tumor necrosis factor-alpha production by tristetraprolin. Science 281:1001-1005.

13. Chan, C. L., and R. Landick. 1989. The Salmonella typhimurium his operon leader region contains an RNA hairpin-dependent transcription pause site. Mechanistic implications of the effect on pausing of altered RNA hairpins. J. Biol. Chem. 264:20796-20804.

14. Cherbas, L., and P. Cherbas. 1993. The arthropod initiator: the capsite consensus plays an important role in transcription. Insect Biochem. Mol. Biol. 23:81-93.

15. Chomczynski, P., and N. Sacchi. 1987. Single-step method of RNA isolation by acid guanidinium thiocyanate-phenol-chloroform extraction. Anal. Biochem. 162:156-159.

16. Culbertson, M. R. 1999. RNA surveillance. Unforeseen consequences for gene expression, inherited genetic disorders and cancer. Trends Genet. 15: 74-80.

17. Fischer, U., J. Huber, W. C. Boelens, I. W. Mattaj, and R. Luhrmann. 1995. The HIV-1 Rev activation domain is a nuclear export signal that accesses an export pathway used by specific cellular RNAs. Cell 82:475-483.

18. Fischer, U., S. Meyer, M. Teufel, C. Heckel, R. Luhrmann, and G. Rautmann. 1994. Evidence that HIV-1 Rev directly promotes the nuclear export of unspliced RNA. EMBO J. 13:4105-4112.

19. Fridell, R. A., H. P. Bogerd, and B. R. Cullen. 1996. Nuclear export of late HIV-1 mRNAs occurs via a cellular protein export pathway. Proc. Natl. Acad. Sci. USA 93:4421-4424.

20. Fridell, R. A., A. M. Pret, and L. L. Searles. 1990. A retrotransposon 412 insertion within an exon of the Drosophila melanogaster vermilion gene is spliced from the precursor RNA. Genes Dev. 4:559-566.

21. Fridell, R. A., and L. L. Searles. 1994. Evidence for a role of the Drosophila melanogaster suppressor of sable gene in the pre-mRNA splicing pathway. Mol. Cell. Biol. 14:859-867.

22. Geyer, P. K., A. J. Chien, V. G. Corces, and M. M. Green. 1991. Mutations in the su(s) gene affect RNA processing in Drosophila melanogaster. Proc. Natl. Acad. Sci. USA 88:7116-7120.

23. Hartzog, G. A., T. Wada, H. Handa, and F. Winston. 1998. Evidence that Spt4, Spt5, and Spt6 control transcription elongation by RNA polymerase II in Saccharomyces cerevisiae. Genes Dev. 12:357-369.

24. Hentze, M. W., and A. E. Kulozik. 1999. A perfect message: RNA surveillance and nonsense-mediated decay. Cell 96:307-310.

25. Higuchi, R. 1990. Recombinant PCR, p. 177-183. In M. A. Innis, D. H. Gelfand, J. J. Sninsky, and T. J. White (ed.), PCR protocols: a guide to methods and applications. Academic Press, Inc., San Diego, Calif.

26. Hilleren, P., and R. Parker. 1999. mRNA surveillance in eukaryotes: kinetic proofreading of proper translation termination as assessed by mRNP domain organization? RNA 5:711-719.

27. Hirose, Y., and J. L. Manley. 1998. RNA polymerase II is an essential mRNA polyadenylation factor. Nature 395: $93-96$

28. Karess, R. E. 1985. P element mediated germ line transformation of Drosophila, p. 121-141. In D. M. Glover (ed.), DNA cloning: a practical approach, vol. 2. IRL Press, Oxford, England

29. Kim, N., J. Kim, D. Park, C. Rosen, D. Dorsett, and J. Yim. 1996. Structure and expression of wild-type and suppressible alleles of the Drosophila purple gene. Genetics 142:1157-1168.

30. Kohler, U., M. Donath, R. R. Mendel, R. Cerff, and R. Hehl. 1996. Intronspecific stimulation of anaerobic gene expression and splicing efficiency in maize cells. Mol. Gen. Genet. 251:252-258.

31. Korb, M., Y. Ke, and L. F. Johnson. 1993. Stimulation of gene expression by introns: conversion of an inhibitory intron to a stimulatory intron by alteration of the splice donor sequence. Nucleic Acids Res. 21:5901-5908.

32. Lai, W. S., E. Carballo, J. R. Strum, E. A. Kennington, R. S. Phillips, and P. J. Blackshear. 1999. Evidence that tristetraprolin binds to AU-rich elements and promotes the deadenylation and destabilization of tumor necrosis factor alpha mRNA. Mol. Cell. Biol. 19:4311-4323.

33. Lange, P., M. Victor, and B. J. Benecke. 1997. Basal level transcription of the human hsp86 gene is directed by intron-based elements. Genes Cells 2:185194.

34. Lazinski, D., E. Grzadzielska, and A. Das. 1989. Sequence-specific recognition of RNA hairpins by bacteriophage antiterminators requires a conserved arginine-rich motif. Cell 59:207-218.

35. Lee, T. X., and L. F. Johnson. 1998. Pre-mRNA processing enhancer (PPE) element increases the expression of an intronless thymidylate synthase gene but does not affect intron-dependent S phase regulation. J. Cell. Biochem. 69:104-116

36. Lindsley, D. L., and G. G. Zimm. 1992. The genome of Drosophila melanogaster. Academic Press, Inc., San Diego, Calif.

37. Liu, X., and J. E. Mertz. 1995. HnRNP L binds a cis-acting RNA sequence element that enables intron-dependent gene expression. Genes Dev. 9:17661780

38. Liu, X., and J. E. Mertz. 1996. Sequence of the polypyrimidine tract of the 3'-terminal $3^{\prime}$ splicing signal can affect intron-dependent pre-mRNA processing in vivo. Nucleic Acids Res. 24:1765-1773.

39. Malim, M. H., L. S. Tiley, D. F. McCarn, J. R. Rusche, J. Hauber, and B. R. Cullen. 1990. HIV-1 structural gene expression requires binding of the Rev trans-activator to its RNA target sequence. Cell 60:675-683.

40. Maquat, L. E. 1995. When cells stop making sense: effects of nonsense codons on RNA metabolism in vertebrate cells. RNA 1:453-465.

41. Maroni, G. 1996. The organization of eukaryotic genes. Evol. Biol. 29:1-19.

42. McCracken, S., N. Fong, K. Yankulov, S. Ballantyne, G. Pan, J. Greenblatt, S. D. Patterson, M. Wickens, and D. L. Bentley. 1997. The C-terminal domain of RNA polymerase II couples mRNA processing to transcription. Nature 385:357-361.

43. Mello, C. C., C. Schubert, B. Draper, W. Zhang, R. Lobel, and J. R. Priess. 1996. The PIE-1 protein and germline specification in C. elegans embryos. Nature 382:710-712.

44. Mount, S. 1993. Messenger RNA splicing signals in Drosophila genes, p. 333-358. In G. Maroni (ed.), An atlas of Drosophila genes. Oxford University Press, New York, N.Y.

45. Murray, M. V., M. A. Turnage, K. J. Williamson, W. R. Steinhauer, and L. L. Searles. 1997. The Drosophila suppressor of sable protein binds to RNA and associates with a subset of polytene chromosome bands. Mol. Cell. Biol. 17:2291-2300.

46. Rethmeier, N., J. Seurinck, M. Van Montagu, and M. Cornelissen. 1997. Intron-mediated enhancement of transgene expression in maize is a nuclear, gene-dependent process. Plant J. 12:895-899.

47. Ruberte, E., T. Marty, D. Nellen, M. Affolter, and K. Basler. 1995. An absolute requirement for both the type II and type I receptors, punt and thick veins, for dpp signaling in vivo. Cell 80:889-897.

48. Rudner, D. Z., R. Kanaar, K. S. Breger, and D. C. Rio. 1996. Mutations in the small subunit of the Drosophila U2AF splicing factor cause lethality and developmental defects. Proc. Natl. Acad. Sci. USA 93:10333-10337.

49. Rutledge, B. J., M. A. Mortin, E. Schwarz, D. Thierry-Mieg, and M. Meselson. 1988. Genetic interactions of modifier genes and modifiable alleles in Drosophila melanogaster. Genetics 119:391-397.

50. Subramanian, T., R. Govindarajan, and G. Chinnadurai. 1991. Heterologous basic domain substitutions in the HIV-1 Tat protein reveal an argininerich motif required for transactivation. EMBO J. 10:2311-2318.

51. Voelker, R. A., W. Gibson, J. P. Graves, J. F. Sterling, and M. T. Eisenberg. 1991. The Drosophila suppressor of sable gene encodes a polypeptide with regions similar to those of RNA-binding proteins. Mol. Cell. Biol. 11:894905.

52. Voelker, R. A., S. M. Huang, G. B. Wisely, J. F. Sterling, S. P. Bainbridge, and K. Hiraizumi. 1989. Molecular and genetic organization of the suppressor of sable and minute (1) $1 \mathrm{~B}$ region in Drosophila melanogaster. Genetics 122:625-642.

53. Wada, T., T. Takagi, Y. Yamaguchi, A. Ferdous, T. Imai, S. Hirose, S. 
Sugimoto, K. Yano, G. A. Hartzog, F. Winston, S. Buratowski, and H. Handa. 1998. DSIF, a novel transcription elongation factor that regulates RNA polymerase II processivity, is composed of human Spt4 and Spt5 homologs. Genes Dev. 12:343-356.

54. Watnick, R. S., and M. E. Gottesman. 1999. Binding of transcription termination protein nun to nascent RNA and template DNA. Science 286:2337-2339. 55. Watnick, R. S., and M. E. Gottesman. 1998. Escherichia coli NusA is re- quired for efficient RNA binding by phage HK022 nun protein. Proc. Natl. Acad. Sci. USA 95:1546-1551.

56. Weiss, M. A., and N. Narayana. 1998. RNA recognition by arginine-rich peptide motifs. Biopolymers 48:167-180.

57. Worthington, M. T., B. T. Amann, D. Nathans, and J. M. Berg. 1996. Metal binding properties and secondary structure of the zinc-binding domain of Nup475. Proc. Natl. Acad. Sci. USA 93:13754-13759. 